\title{
Research on the Influential Mechanism of International Team Performance
}

\author{
Song Chengcheng \\ Department of Business Administration \\ School of Management, Zhejiang University \\ Hangzhou, Zhejiang, P.R.China \\ fendou1374@126.com
}

\begin{abstract}
This literature's hereof purpose is to detect several key variables such as team form, team cohesion, and team cognition affect team's achievement on base of analysis of International Team frame structure and historic researches. Moreover influential mechanism was set up about International Team performance, raised 4 assumptions to prove those variables positive or minus influence each other and to team performance. As predicted, international team form has positive influence on team's cohesion, but negative influence on team's cognition. On the other hand, international team cohesion and cognition have positive impact on team's performance.
\end{abstract}

Keywords-influential mechanism; global team; team performance; team cohesion; team cognition

\section{INTRODUCTION}

In this era of globalization, Chinese companies are gradually shifting from traditional state-owned firms to multinational corporation (MNC) nowadays. Moreover, not only Chinese firms are changing, but also world famous multinational groups, which bring with new technology, advanced management skills, as well as new opportunities to our country, are taking efforts ever since Chine became part of WTO. This trend indicated that international enterprises now are playing a vital role in today's world, especially in impacting economics world wildly.

Therefore, all these super powered enterprises are becoming our domestic firms main competitors in present business world. Meanwhile, multi-national operation has also been the major approach, which is most commonly used by Fortune 500, in international expansion process to win a competitive edge. MNC has its advantages in avoiding trade barrier, achieving scale economics, and unified allocation of resources.

However, one of the most important issues of multinational operation is the global team performance improvement. International team is a true collection of talents across cultures and boundaries. So team members may come from different countries, different nationalities with different cultural background, that bring troubles to cross-culture management in multinational organizations. Meanwhile, there are actually few local China companies can jump out pattern of traditional management, and operate their business strategy in a globalized way. Therefore, it becomes necessary to investigate how to enhance team performance by manage international team more reasonable. .

\section{LITERATURE REVIEW}

Sumantra Ghoshal and Christopher A. Bartlett (1990) defined a multinational corporation as a group of geographically dispersed and organizations with goal disparate from one to another, which include its headquarters and the different national subsidiaries. And Govindarajan and Gupta (2001) believed that global team is a special organization unlike any other, which business license should be multi-national. According to theory brought out by Mazenevski and Chudoba in 2000, global teams are groups of people who are 1) identified by their organizations and members as a team; 2) making and implementing company's global strategy; 3) interacting and communicating through web-based technology rather than face-to-face; 4) working and living across space in different countries.

Regarding team co mposition, first of all, composition of a team is becoming diversified due to dynamic changes of demographic distribution and constitution, as well as the development of new organizational model (Zenger and Lawrence, 1998). In general, factors related to work environment including nationality, gender, age, etc., would lead to a more different result of team performance rather than team players' experience, educational level and work skills. This theory has been tested by previous studies (Ayub et al.,2006) that diversity nationalities and gender may hinder group interaction, and further may cause damage to team

Meanwhile, current researches (Williams, 1998; Webber, S. S. and L. M. Donahue, 2001) are emphasizing on how to open the black box of population characteristics of organization, to explain cohesion and cognition. These studies enriched and developed classical team diversification theory and in turn provided a better explanation on team ach ievement.

Generally speaking, team performance is an output variable, which can be tested based on three dimensions: outcomes of activities, effectiveness of the whole group and high potential development of team members (Hackman, 1990).

Based on previous studies (Hambrick, D.C., 1994; Susan E.J. and Niclas L. E, 2003) the main purposes of this research is to analysis the impact and applications of 
team composition, team cohesion and team cognition on team achieve ment.

\section{MODEL AND HYPOT HESES}

\section{A. Variables Definition}

\section{1) Global Team Composition:}

Diversified international teams are more likely to generate creative solutions, as they usually hold rich information and extensive resources (Chen and Klimoski, 2003). Gully, Incalcaterra, Joshi and Beaubien (2006) has indicated in their study that the diversity of global team nationality will be the main factor to be tested about its influence on team cohesion and cognition.

2) Global Team Cohesion and Cognition:

In line with previous studies (Salas \& Fiore, 2007), team cognition is the interre lationship between process, where encoding, storage and retrieval of information are applied on team.

Research conducted by Reagans and McEvily (2003) indicated in their studies that team cohesion is the motivation and individual's willingness to spend much time and efforts to share information with others to achieve the goal of whole team

\section{3) Global Team Performance}

Team performance is constitute with complex factors, and varies from one to another because of its methodology. Maznevski and Chudoba (2000) found that team performance could be evaluated by quality of strategy, quality of execution, and individual cohesions to the group.

\section{B. Hypotheses}

Hypotheses 1: There is positive correlation between Team Cohesion and Team Achievement.

Hypotheses 2: There is positive correlation between Team Cognition and Team Achievement.

Hypotheses 3: There is negative correlation between Team Nationality Diversity and Team Cohesion.

Hypotheses 4: There is positive correlation between Team Nationality Diversity and Team Cognition.

\section{Model of Influential Mechanism of International Team Achievement}

Based on above search of previous studies, the main focus of our study is to examine the influential mechanism of international team achievement as following model:

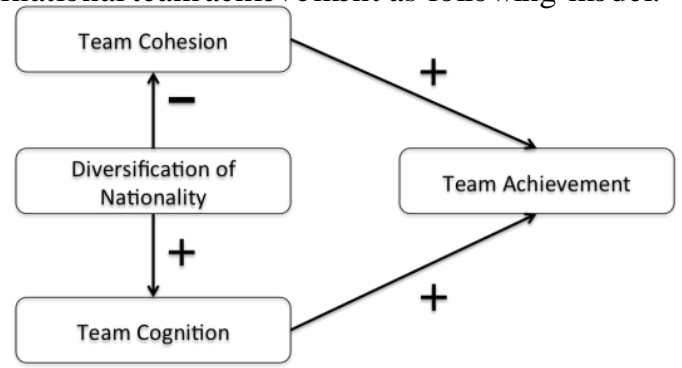

Figure 1. Model of Influential Mechanism of International Team Achievement

\section{RESEARCH METHODS DESIGN}

To test these hypotheses above, the data is analyzed to verify the model in two aspects: (1) Use correlation analysis and regression analys is to measure the relation among international team composition, team cohesion and team cognition. (2) Use correlation analysis and regression analysis to measure the affect to team me mbers' achievement by international team composition, team cohesion, and team cognition.

This study polled 45 international teams from Shenzhen (CHINA), Russia, Northeast Europe and other 9 areas. From all the 196 questionnaires sent, we received 158 replies from 30 international teams. 150 replies are effective and the final effective recovery ratio of questionnaires is $76.39 \%$, while the effective response rate is $94.93 \%$.

Among 30 responded teams, there are 6 marketing teams, 5 research and development teams, and 16 production or quality management teams. These 30 managers of the teams also verified their teams in 3 as pects: (1) team achievement (2) team productivity and efficiency (3) recognition among other teams surrounded.

\section{DAT A ANALYSIS}

Use correlation analysis and regression analysis methods to measure the influence to the international team achievement of factors. Use SPSS to complete descriptive statistics, correlation analysis and regression analys is. The grades in the team dimension are calculated with an average of all team me mbers.

\section{A. Team Nationality Diversity and Team Cohesion Correlation and Significant Analysis}

Table 1 reports the outcome of Pearson correlation data analysis. The correlation between Team Nationality Diversity and Team Cohesion is 0.109 , which shows a positive correlation between Team Nationality Diversity and Team Cohesion.

Table 2 reports the outcome of significant analysis. In the test of $\mathrm{H} 3$, the coefficient on Team Nationality Diversity and Team Cohesion is 0.568>0.1, which can't show a significant correlation between Team Nationality Diversity and Team Cohesion.

In conclusion, there isn't a significant correlation between Team Nationality Diversity and Team Cohesion. $\mathrm{H} 3$ is verified FALSE.

TABLE I. TEAM COMPOSITION, TEAM COHESION AND TEAM COGNITION CORRELATION ANALYSIS

\begin{tabular}{lccc}
\hline & 1 & 2 & 3 \\
\hline 1.Team Nationality Diversity & 1 & & \\
2. Team Cohesion & 0.109 & 1 & \\
3. Team Cognition & $.556^{* *}$ & 0.109 & 1 \\
\hline
\end{tabular}

TABLE II. TEAM COMPOSITION, TEAM COHESION AND TEAM COGNITION SIGNIFICANT ANALYSIS

\begin{tabular}{lccc}
\hline & 1 & 2 & 3 \\
\hline 1.Team Nationality Diversity & 1 & & \\
2. Team Cohesion & 0.568 & 1 & \\
3. Team Cognition & 0 & 0.568 & 1 \\
\hline
\end{tabular}




\section{B. Team Nationality Diversity and Team Cognition Correlation and Significant Analysis}

Table 1 reports the outcome of Pears on correlation data analysis. The correlation between Team Nationality Diversity and Team Cognition is 0.556 , which shows a positive correlation between Team Nationality Diversity and Team Cognition.

Table 2 reports the outcome of significant analysis. In the test of $\mathrm{H} 4$, the coefficient on Team Nationality Diversity and Team Cognition is $0.000<0.1$, which shows a significant correlation between Team Nationality Diversity and Team Cognition.

In conclusion, there is a significant correlation between Team Nationality Diversity and Team Cognition, which means the more dispersed the home countries of team members, the higher the international awareness. $\mathrm{H} 4$ is verified TURE.

\section{Team Cohesion and Team Achievement and Significant Analysis}

Table 3 reports the outcome of Pears on correlation data analysis. The correlation between Team Cohesion and Team Achievement is 0.686 , which shows a positive correlation between Team Cohesion and Team Achievement.

Table 4 reports the outcome of significant analysis. In the test of H1, the coeffic ient on Team Cohesion and Team Achievement is $0.005<0.1$, which shows a significant correlation between Team Cohesion and Team Achievement.

In conclusion, there is a significant correlation between Team Cohesion and Team Achievement, which means the higher the team cohesion, the better the performance of the international team. $\mathrm{H} 1$ is verified TURE.

TABLE III. TEAM COHESION, TEAM COGNITION AND TEAM ACHIEVEMENT CORRELATION ANAL YSIS

\begin{tabular}{lrrr}
\hline & 1 & 2 & 3 \\
\hline 1. Team Cohesion & 1 & & \\
2. Team Cognition & & 1 & \\
3. Team Achievement & $.686 * *$ & $.702 * *$ & 1 \\
\hline
\end{tabular}

TABLE IV. TEAM COMPOSITION, TEAM COHESION AND TEAM COGNITION SIGNIFICANT ANALYSIS

\begin{tabular}{lccc}
\hline & 1 & 2 & 3 \\
\hline 1.Team Nationality & 1 & & \\
Diversity & & 1 & \\
2. Team Cohesion & 0.005 & 0 & 1 \\
3. Team Cognition & 0 \\
\hline
\end{tabular}

D. Team Cognition and Team Achievement and Significant Analysis

Table 3 reports the outcome of Pears on correlation data analysis. The correlation between Team Cognition and Team Achievement is 0.702 , which shows a positive correlation between Team Cognition and Team Achievement.

Table 4 reports the outcome of significant analysis. In the test of $\mathrm{H} 2$, the coefficient on Team Cognition and Team Achievement is $0.000<0.1$, which shows a significant correlation between Team Cognition and Team Achievement.

In conclusion, there is a significant correlation between Team Cognition and Team Achieve ment, which means the higher the team cognition, the better the performance of the international team. $\mathrm{H} 2$ is verified TURE.

\section{RESULTS AND DISCUSSION}

\section{A. Results}

The results showed that team members' diversification of nationality had no significant effect on team's cohesion. However, it also suggested that the higher degree of diversification of members' nationality, the better teammembers' awareness. This phenomenon demonstrated heterogeneity of team members had negative or positive impacts on cohesion, awareness respectively. In addition, the cohesion and awareness of international team had significantly positive effects on performance of the team, reflecting the highly improvement of team's output with cohesive and consistent performance. The higher integrated cognition of team, the more fully use and sharing of knowledge and information, the better performance of the international team.

\section{B. Practical Signficance}

By demonstrating the performance-relevant model of international team and related assumptions, this study confirmed the influence of cohesion, awareness and composition on international team's performance. It constructed the model of mechanism on international team's performance as well.

The conclusions of this study have certain guiding significance for management practices of multinational team and international team. In a sense, this paper has figured out a clear thinking method and approach, which might be beneficial for effective management and operation of team and thus can contribute to promote the performance of international team.

\section{Suggestion for Future Research}

Based on the key variables and research method, further research may focus on following fields.

In order to explain and analyze the impact of nationality diversification to intermediate variables, other factors such as faith, culture, education, knowledge and skills can be measured.

Apart from the influence of cohesion and awareness of the team, other dimensions might help us refine new theory. For example, in a setting of cultural integration, there have been a number of researches on investigating what impact of the combination of consistency and cognition to team performance.

\section{REFERENCES}

[1] Bartlett, C.A. and Ghoshal, S., Managing Across Borders: The Transnational Solution [M], Harvard Business Press, Boston:

[2] Govindarajan, V., \& Gupta, A. K, The quest for global dominance[M].San Francisco, CA: Jossey Bass, 2001.

[3] Maznevski, M. L., \& Chudoba, K. M, Bridging space over time: Global virtual team dynamics and effectiveness. Organization Science[J], 2000, 11: 473-485. 
[4] Zenger, T.R. \& Lawrence, B.S. 1989. Organizational demography: The different effects of age and tenure distributions on technical communication[J]. Academy of Management Journal, 32:353-376.

[5] Williams K Y, O'Reilly C A. Demography and diversity in organizations: A review of 40 years of research. Research in organization behavior[J], 1998, 20: 77 140.

[6] Williams K Y, O'Reilly C A. Demography and diversity in organizations: A review of 40 years of research. Research in organization behavior[J], 1998, 20: 77 140

[7] Stagl, K. C., Salas, E., \& Fiore, S. M. (2007). Best practices in cross trainin teams. In D. A. Nembhard (Ed.), Workforce cross training handbook (pp. 156-175)[M]. Boca Raton, FL: CRC Press.

[8] Chen, G., \& Klimoski.R.J. The impact of expectations on newcomer performance in teams as mediated by work characterstics, social exchange and empowerment [J]. Academy of Management Journal,2006,49:106-117
[9] Gully, S. M., Incalcaterra, K. A., Joshi, A., \& Beaubien, J. M., A meta-analysis of team-efficacy, potency, and performance: Interdependence and level of analysis as moderators of observed relat ionships[J]. Journal of Applied Psychology, 2003,87: 819-832.

[10] Reagans, R. and McEvily, B., Network Structure and Knowledge Transfer: The Effects of Cohesion and Range.[J] Administrative Science Quarterly,(2003), 48, 240-267:

[11] Hambrick, D. C, Top management groups: A conceptual integration and reconsideration of the "team" label. [J]Research in Organizational Behavior, 1994, 16: 171-212

[12] Susan E J, Aparna J, Niclas L E. Recent research on team and organizational diversity: SWOT analysis and implications. [J]Journal of management, 2003, 29(6): 801 830.

[13] Mullen, B. and Copper, C. The relation between Group cohesiveness and Performance: An integration [J]. Journal of Applied Psychology, 2000,85:612 622 